\title{
A Study on Spatial Distribution and Characteristics of Moving Companies
}

\author{
Dae Hyun Seo, Kabsung Kim \\ Yonsei University, Seoul, South Korea \\ Email:nanumdle@naver.com,kabsung@yonsei.ac.kr
}

How to cite this paper: Seo, D.H. and Kim, K. (2018) A Study on Spatial Distribution and Characteristics of Moving Companies. Theoretical Economics Letters, 8, 316-329. https://doi.org/10.4236/tel.2018.83022

Received: November 28, 2017

Accepted: February 8, 2018

Published: February 11, 2018

Copyright $\odot 2018$ by authors and Scientific Research Publishing Inc. This work is licensed under the Creative Commons Attribution International License (CC BY 4.0).

http://creativecommons.org/licenses/by/4.0/

\section{cc) (i) Open Access}

\begin{abstract}
The purpose of this study is to propose a method of establishing demand zone in the estimation of industrial complex needs. Demand estimates of existing industrial complexes are mainly based on survey method, which leads to excessive or underestimated demand depending on the extracted samples. Therefore, it has been argued that there is a need to analyze what movements the companies actually show. In this study, based on the status of about 450,000 companies included in the Hankyung Business Yearbook, the company DB book in Korea, each company analyzed the movement and the moving area by city, and based on this, the O-D table was created. This study will empirically validate the previous demand of the enterprises and provide information related to the establishment of the demand for the industrial complex in the future, which will contribute to the estimation of the actual demand of the industrial complex.
\end{abstract}

\section{Keywords}

Industrial Complex, Industrial Land Use, Spatial Distribution of Companies, Characteristics of Companies, Company Movement

\section{Introduction}

One of the Key projects in local industrial policy is the creation of industrial complexes. So, the government has supplied them to fulfill the policy goals in order to achieve the national economic growth.

In Korea, there are many industrial complexes have been built since to 1960 's, and many of them were constructed by the government to achieve the government's industrial upbringing policy. In the beginning, national economic environment is very poor in Korea, so it was necessary to concentrate national competence in some areas. For example, "A Special Act on Land Acceptance for the 
Creation of Industrial Zone" was enacted in 1962, "Act on the Development of industrial Complex for the Export Industry Development" was established in 1964. As a result, industrial complexes were established in the 1960 s to foster export industries centered on light industry. On the other hand, in the 1970s, industrial parks were built around the Southeast region in accordance with the policies for the promotion of heavy chemical industry. After the 1980s, large scale industrial complexes were built around the backward regions to achieve balanced national development.

As we have seen in the previous case, industrial parks in Korea are the main means of achieving government policy goals. In addition to its role as a hub for fostering strategic industries that are the basis of national economic growth, it has played an important role in the development of national industries by inducing the growth of underdeveloped regions and alleviating regional gaps in growth. It seems to be further expanded.

However, current industrial parks in Korea are becoming less competitive due to the price of land, and demand and supply imbalances are not achieved due to the lack of actual demand for new industries. In particular, in order to estimate the demand for industrial complexes, we follow the existing methods that depend on the questionnaire. Therefore, there is a problem that the demand is under- or over-estimated. Estimation of demand in the development of industrial complex is a very important process because it is the basis for establishing the size of industrial land use supply. It is a time when theoretical and empirical research is needed.

\section{Literature Reviews}

\subsection{Industrial Demand Estimation Theories}

Demand estimates of industrial complex can be divided into quantitative methods and survey methods. The quantitative methods have the following models. The time series model is a method of predicts future trends based on observed patterns in the past time series. When the growth rate gradually decreases when there is an upper limit of the observed data and it increases by more than a certain level, the modified index model, the Gompertz model, and the logistic model are used. In the case of the smoothing method which linearized the variation of time series data and grasps future trends, simple exponential smoothing method, linear moving average method, linear exponential smoothing method, and second exponential smoothing method are utilized. In addition, there are probabilistic time series models that probabilistically estimate future trends based on regular patterns of time series data, and AutoRegression (AR), Moving Average (MA), AutoRegression Moving Average (ARMA), and AutoRegression Integrated Moving Average (ARIMA) are mainly used.

The regression model estimates regression curves by using production function or panel data and estimates industrial demand based on this. The regression model is complementary to the time series model because it estimates the de- 
mand by reflecting the future economic structure. In the case of a multiple regression model using production function, it is a method to estimate the demand by modeling the linear relationship between the predicted variable and the result variable, and it is a merit that various socioeconomic factors can be reflected in the model. In general, Cobb-Douglas production function is used to estimate the model based on the production function reflecting capital, labor, and land. The panel regression model can reflect both time and space factors at the same time, which is a good way to estimate regional demand.

In the case of basic unit model, it is a method to calculate the total demand area by reflecting the future production amount or the number of workers to the area of the site per unit of production or per worker. This is a method of estimating future demand based on the assumption that the amount of unit production and the area required for each worker exist. It is useful because it is simple to use and can reflect various analysis methods at the same time. Japan and the UK are using this method to estimate demand for industrial sites. In Japan, the use of unit method is applied based on the amount of production by industry in the target year, and in the UK, it is recommended to use the unit method based on the prospect of employment size.

The survey method collects the responses directly or indirectly using standardized questionnaires to the subjects selected by certain criteria, and draws conclusions analyzing them. In Korea, the feasibility study method for estimating demand for industrial sites is set by law, and the questionnaire method is applied here. The sampling method of the questionnaire is using the allocation sampling, and the sampling frame uses the company information data.

\subsection{Precedent Researches and Conclusion}

In Korea, there are few studies related to the estimation of industrial complex demand, and most of them were analyzed using statistical data for empirical analysis. [1] estimated the real value added by analyzing the value-added projections of industry and the factors affecting the future economic growth, and then derived the land supply coefficient by using industry value-added amount and land area based on this, Respectively. [2] examined the changes in the demand trends of the manufacturing industry according to the changes in the metropolitan area by using the mining and manufacturing statistics, and conducted a survey of 440 manufacturing companies with 10 or more employees nationwide. Questionnaire survey was conducted to investigate the preference of location and the intention to expand or expand in the future. [3] estimated the empirical relationship between the industrial complex demand and the future demand based on the estimated coefficients, using the statistical data of the National Statistical Office to predict the industrial complex demand. In order to forecast demand, we estimated the demand for future land area and estimated the probability of locating a particular area in the Seoul metropolitan area and the capital area using the binary logit model. [4] estimated the parameters by using the 
panel cointegration relation between the industrial site and the production volume for estimating the demand of the industrial land, and presented the demand forecast of the industrial land based on this. For this purpose, annual statistics of site area and production amount by industry were utilized from 1982 to 2009.

In addition to the case of Korea, related research is as follows. [5] focuses on the determination of industrial and commercial land use in urban development, using a spatial data analysis method in the period of 2000-2010 in Beijing. In this study, exploring the impact of spatial independent variables on these two types of land use, using spatial logistic analysis. [6] aims to examine the influence of government and industrial agglomeration on industrial land prices by constructing hedonic pricing functions, using 693 industrial land parcels from 2002 to 2006 provided by public sector and private developers. In [7], land use change dynamics were investigated by the combined use of satellite remote sensing, Geographic information systems (GIS), and stochastic modelling technologies in Zhujiang Delta of China.

In this way, it is found that the existing researches have made a lot of studies to predict demand statistically using statistical data in Korea. It can be said that it is useful in that it can save time and cost in estimating demand based on data and estimation process is reasonable, but it is inappropriate to reflect the movement of actual companies. On the other hand, studies using spatial data such as satellite images and GIS have been attempted in overseas studies. However, it is pointed out that these data are not easy to obtain and analysis is also in the initial stage. Therefore, in this study, based on the actual company data, it is necessary to examine how far the companies moved in the area and where they moved, it is meaningful. Above all, this study can be said to be different from existing researches in that it can construct data that can substitute without using statistical data related to industry, and can carry out research on industrial transfer based on this.

\section{Database Analysis}

In this study, "Hankyung Company Overview" published by the Korea Economic Daily was used for setting the demand zone. The Hankyung Enterprise Overview is a corporate DB data set out to identify the current status and financial information of individual companies based on audit reports, financial reports, and company surveys of Korean companies held by the Financial Supervisory Service and NICE evaluation information. In this study, the change of the address of the company is described as the transfer of the company, and based on this, the transfer demand of the companies is grasped.

The data used in this study were obtained from the data for 7 years from 2011 to 2017, and the same company was examined through business number matching. The collected data were analyzed by data cleaning process. Data cleaning process was performed by extracting valid data that can be analyzed from the 
entire data. It was based on the existence of the business number that can be confirmed as the same company and the address information at the district level to identify whether the company was transferred. There are two problems occurred in this process. First, data is missing that can't be confirmed as a company number or address is missing. In this case, the data of the company without the business number was deleted. In the case of the data without address in 2017, the business information was searched by using the business number, and the confirmed address information was directly inputted to the city district level.

Second, there were some areas where the address system changed partly due to the change of administrative districts, including Changwon City, Cheongju City and Sejong City. In the case of Changwon City and Cheongju City, the previous administrative area was changed to the changed administrative area. On the other hand, in case of Sejong City, in addition to the whole of Yeongi Gun, some of Gongju City and Cheongwon Gun are included. In this study, Yeongi Gun was included.

For reference, address information was extracted to the city district level. Therefore, if the company moves within the municipal district, it is not identified as the company movement. In addition, it should be noted that former information was handled only at the metropolitan level. The current status of the company subject to analysis is as follows. About 1.05 million companies have been acquired through the DB, and 451,543 data with business number and address information (Table 1).

According to the data of the National Statistical Office in Korea, the total number of company in 2015 is about 3.87 million, and regional distribution between analyzed data and statistical data are as follows (Table 2).

In order to test whether the analytical data reflects the present status of statistical distribution, we conducted a paired t-test and confirmed that the null hypothesis that the two groups are equal at the $1 \%$ significance level cannot be rejected. Therefore, it can be seen that the data used in this study reflects the distribution of actual companies to some extent (Table 3 and Table 4).

Table 1. Number of company.

\begin{tabular}{ccc}
\hline \multirow{2}{*}{ Year } & \multicolumn{2}{c}{ Number of company } \\
\cline { 2 - 3 } & Number of Database & Analysis Target \\
\hline 2011 & 150,815 & 143,793 \\
2012 & 208,902 & - \\
2013 & 152,727 & - \\
2014 & 164,675 & - \\
2015 & 172,539 & 104,176 \\
2017 & 206,731 & 203,574 \\
Total & $1,056,389$ & 451,543 \\
\hline
\end{tabular}

Source: The Korea economic daily, Hankyung company overview (2011-2017). 
Table 2. Spatial distribution of company.

\begin{tabular}{cccccccc}
\hline \multirow{2}{*}{ Region } & \multicolumn{3}{c}{ Analytical data } & \multicolumn{3}{c}{ Statistical data } \\
\cline { 2 - 7 } & 2011 & 2015 & 2017 & Total & $\%$ & 2015 & $\%$ \\
\hline Gangwon-do & 3083 & 2028 & 4232 & 9343 & 2.07 & 133,517 & 3.45 \\
Gyeonggi-do & 29,382 & 23,069 & 47,485 & 99,936 & 22.13 & 827,983 & 21.37 \\
Gyeongsangnam-do & 9590 & 6735 & 12,161 & 28,486 & 6.31 & 262,950 & 6.79 \\
Gyeongsangbuk-do & 5768 & 4455 & 8649 & 18,872 & 4.18 & 218,796 & 5.65 \\
Gwangju & 4375 & 4936 & 8384 & 16,902 & 3.74 & 113,424 & 2.93 \\
Daegu & 4472 & 4143 & 6143 & 13,364 & 2.96 & 200,070 & 5.16 \\
Daejeon & 3416 & 2560 & 5287 & 11,263 & 2.49 & 111,815 & 2.89 \\
Busan & 8937 & 6233 & 11,014 & 26,184 & 5.80 & 278,850 & 7.20 \\
Seoul & 46,295 & 29,937 & 56,199 & 132,431 & 29.33 & 820,658 & 21.18 \\
Sejong & 262 & 372 & 824 & 1458 & 0.32 & 10,480 & 0.27 \\
Ulsan & 2898 & 2258 & 3987 & 9143 & 2.02 & 80,805 & 2.09 \\
Incheon & 5829 & 4113 & 8413 & 18,355 & 4.06 & 186,011 & 4.80 \\
Jeollanam-do & 5499 & 4896 & 9450 & 19,845 & 4.39 & 147,198 & 3.80 \\
Jeollabuk-do & 4159 & 2987 & 6154 & 13,300 & 2.95 & 146,654 & 3.79 \\
Jeju-do & 1348 & 1191 & 2339 & 4878 & 1.08 & 55,155 & 1.42 \\
Chungcheongnam-do & 4560 & 3596 & 7109 & 15,265 & 3.38 & 158,308 & 4.09 \\
Chungcheongbuk-do & 3920 & 2854 & 5744 & 12,518 & 2.77 & 121,493 & 3.14 \\
Total & 143,793 & 106,363 & 203,574 & 451,543 & 100.0 & $3,874,167$ & 100.0 \\
\hline
\end{tabular}

Source of statistical data: national statistical office in Korea, census on establishments (2015).

Table 3. Paired samples statistics.

\begin{tabular}{ccccc}
\hline Variable & Mean & N & Std. Deviation & $\begin{array}{c}\text { Std. Error } \\
\text { Mean }\end{array}$ \\
\hline D_Data & $26,561.3529$ & 17 & $34,883.79272$ & 8460.56247 \\
D_Stat & $227,892.1756$ & 17 & $234,709.2912$ & $56,925.36464$ \\
\hline
\end{tabular}

Table 4. Paired t-test between analytical data and statistical data.

\begin{tabular}{cccc}
\hline Variable & $\mathrm{t}$ & $\mathrm{df}$ & Sig. $(\mathrm{p})$ \\
\hline D_Data - D_Stat & -4.133 & 16 & 0.001 \\
\hline
\end{tabular}

\section{Results}

Of the 451,543 companies surveyed, 20,670 were transferred to the companies identified through address information. Seoul is the region with the highest number of moving in and out companies (Table 5).

\subsection{Results from the Region Side}

In Table 5, Seoul (R9) is the region with the largest number of companies moving. In terms of business inflows, Seoul has superior industrial infrastructures than other regions. In Table 2, 20\% of the national enterprises are located in Seoul and 
Table 5. O-D table about moving company (region level).

\begin{tabular}{|c|c|c|c|c|c|c|c|c|c|c|c|c|c|c|c|c|c|c|}
\hline \multirow{2}{*}{$\begin{array}{c}\text { Moving } \\
\text { out }\end{array}$} & \multicolumn{18}{|c|}{ Moving in } \\
\hline & R1 & R2 & R3 & $\mathrm{R} 4$ & R5 & R6 & R7 & R8 & R9 & R10 & R11 & $\mathrm{R} 12$ & R13 & R14 & R15 & R16 & R17 & Total \\
\hline R1 & 119 & 34 & 5 & 8 & - & 2 & 1 & 4 & 14 & 4 & 1 & 4 & 8 & 12 & 3 & 5 & 9 & 233 \\
\hline R2 & 71 & 2408 & 30 & 42 & 26 & 25 & 30 & 28 & 579 & 18 & 8 & 204 & 43 & 41 & 18 & 193 & 110 & 3874 \\
\hline R3 & 16 & 29 & 406 & 44 & 6 & 7 & 3 & 160 & 25 & 3 & 26 & 1 & 24 & 12 & 16 & 17 & 15 & 810 \\
\hline R4 & 3 & 40 & 18 & 254 & 4 & 87 & 3 & 15 & 36 & 2 & 25 & 6 & 11 & 8 & 4 & 22 & 7 & 545 \\
\hline R5 & 1 & 18 & 2 & 3 & 554 & 1 & 4 & 2 & 21 & 11 & 5 & 2 & 197 & 20 & 2 & 3 & 2 & 848 \\
\hline R6 & 2 & 26 & 13 & 153 & 2 & 412 & 8 & 6 & 21 & 1 & 1 & 1 & 4 & 2 & 2 & 3 & & 657 \\
\hline R7 & 3 & 24 & 8 & 3 & 2 & 8 & 370 & 4 & 35 & 45 & 2 & 2 & 6 & 7 & 2 & 63 & 22 & 606 \\
\hline R8 & 2 & 17 & 166 & 12 & & 3 & 5 & 1059 & 43 & 1 & 19 & 3 & 9 & 8 & 5 & 3 & 1 & 1356 \\
\hline R9 & 57 & 1939 & 34 & 50 & 25 & 17 & 29 & 59 & 5656 & 10 & 14 & 137 & 33 & 32 & 23 & 76 & 49 & 8240 \\
\hline R10 & 1 & 10 & & 2 & 4 & 2 & 10 & & 2 & & & 3 & 5 & 5 & & 36 & 16 & 96 \\
\hline R11 & 1 & 6 & 12 & 32 & & 1 & & 18 & 12 & & 301 & 2 & 1 & 1 & 2 & 3 & 3 & 395 \\
\hline R12 & 10 & 301 & 5 & 5 & 4 & 2 & 5 & 2 & 86 & 10 & & 462 & 7 & 8 & 2 & 40 & 16 & 965 \\
\hline R13 & 3 & 36 & 11 & 10 & 148 & 2 & 1 & 14 & 23 & 11 & 2 & 4 & 508 & 33 & 6 & 10 & 4 & 826 \\
\hline R14 & 3 & 23 & 6 & 4 & 14 & & 5 & 8 & 13 & 8 & 1 & 5 & 23 & 262 & 4 & 13 & 1 & 393 \\
\hline R15 & 4 & 12 & 2 & & 1 & & & 1 & 5 & 2 & 2 & 1 & 3 & 1 & 17 & 1 & & 52 \\
\hline R16 & 5 & 80 & 11 & 8 & 3 & 5 & 28 & 2 & 30 & 56 & 5 & 10 & 15 & 20 & 3 & 170 & 30 & 481 \\
\hline R17 & 6 & 45 & 13 & 13 & 3 & 3 & 18 & & 33 & 30 & 1 & 2 & 3 & 6 & 2 & 15 & 100 & 293 \\
\hline Total & 307 & 5048 & 742 & 643 & 796 & 577 & 520 & 1382 & 6634 & 212 & 413 & 849 & 900 & 478 & 111 & 673 & 385 & 20,670 \\
\hline
\end{tabular}

Notes: R1 (Gangwon-do), R2 (Gyeonggi-do), R3 (Gyeongsangnam-do), R4 (Gyeongsangbuk-do), R5 (Gwangju), R6 (Daegu), R7 (Daejeon), R8 (Busan), R9 (Seoul), R10 (Sejong), R11 (Ulsan), R12 (Incheon), R13 (Jeollanam-do), R14 (Jeollabuk-do), R15 (Jeju-do), R16 (Chungcheongnam-do), R17 (Chungcheongbuk-do).

$30 \%$ of the analyzed companies. So, it is highly probable that agglomeration economy from the transfer company will occur. In addition, Korea's major conglomerates are headquartered in Seoul, and have higher education institutions such as universities. Therefore, it is advantageous for the exchange of knowledge and talent to improve the competence of the company, and the possibility of innovation is higher than other regions.

On the other hand, in terms of corporate outflow, Seoul has high fixed costs due to high land prices and high labor costs. In addition, the Seoul metropolitan area is limited in terms of business expansion, and in the case of other attempts, various supports are provided for attracting companies, so that it can be said that the economic incentives for transferring the business are sufficient. The fact that there are many corporations is also one of the reasons why the number of absolute outflow companies is analyzed.

When the data were reviewed, a total of 6634 companies moved from other regions and 8240 companies moved to other regions. According to the data, it was analyzed that the net outflow of 1606 occurred in Seoul during the period. 
The net outflows of companies in most of the regions were found to be Gyeonggi-do, which was the largest in the region, and the outflows were also found in Incheon, Gangwon-do and Chungcheongnam-do. On the other hand, Daegu and Daejeon showed some net inflows. These results demonstrate that the effect of the regional dispersion policy of the government was successful in Seoul, but the effect is limited because most companies moved to Gyeonggi-do. On the other hand, Gangwon-do and Chungcheongnam-do seem to have succeeded in attracting companies in the metropolitan area. It seems that the two regions are adjacent to the metropolitan area, and the transportation and industrial infrastructures are improved by local policy support (Figure 1, Table 6).

Gangnam-gu is the largest number of company moving district, and $70.9 \%$ of the total outflow companies and $80.4 \%$ of the total inflow companies are moving in Seoul. The spatial distribution of the former companies in Gangnam-gu is as follows (Figure 2, Table 7).

\subsection{Results from the High-Growth Company}

In Korea, policy support is provided to companies with high growth potential. To this end, we set up high-growth companies, which are enterprises with more than 10 employees and an increase in sales or employees by an average of more than $10 \%$ a year.

In this study, we examined the current state of high-growth companies. In 2015-2017, the number of enterprises that meet the standards of high-growth companies among the previous companies is 1734 , which is almost $8.4 \%$ of the total number of moving companies (Table 8).

In Seoul (R9), the number of high-growth companies was also higher, and the number of outflows to Gyeonggi-do was relatively high. On the other hand, outflows to other regions were not so high. Figure 3 shows the regional distribution of high-growth companies moving in Seoul. Compared with Figure 1, which

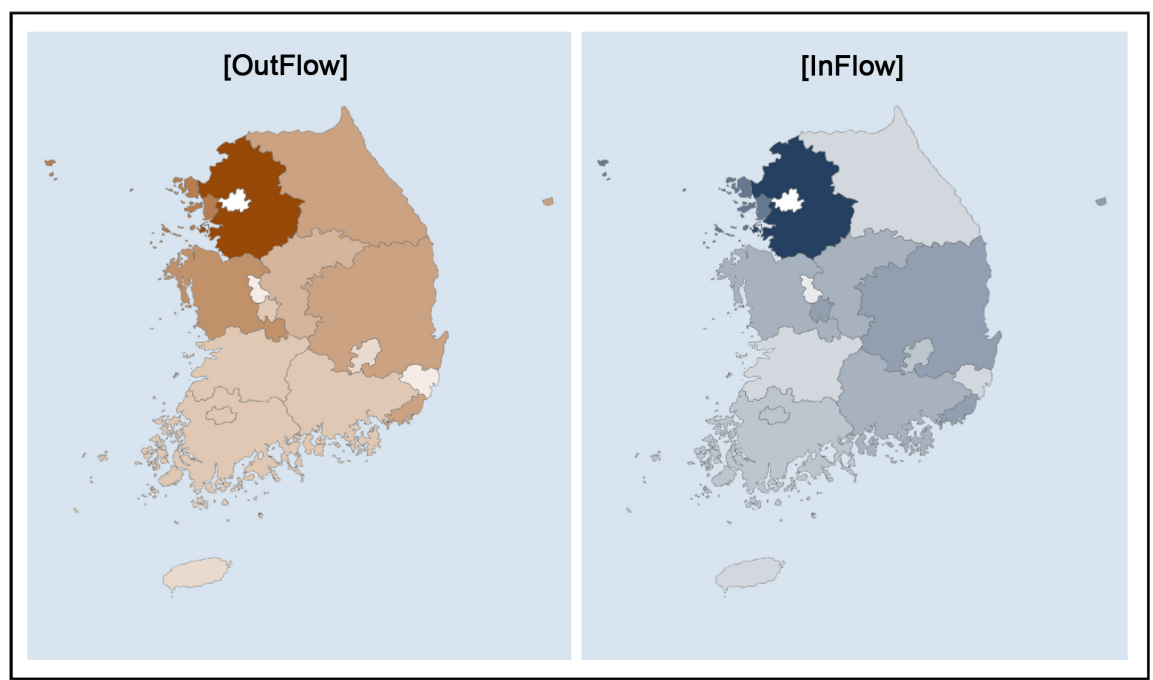

Figure 1. Net flows in Seoul (region level). 


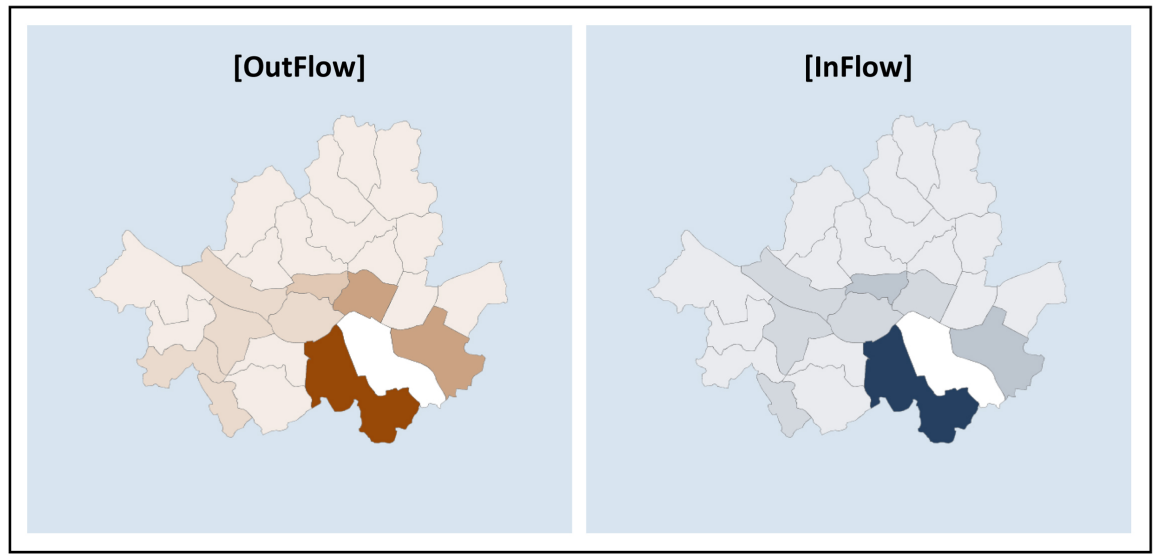

Figure 2. Net flows in Gangnam-gu (district level).

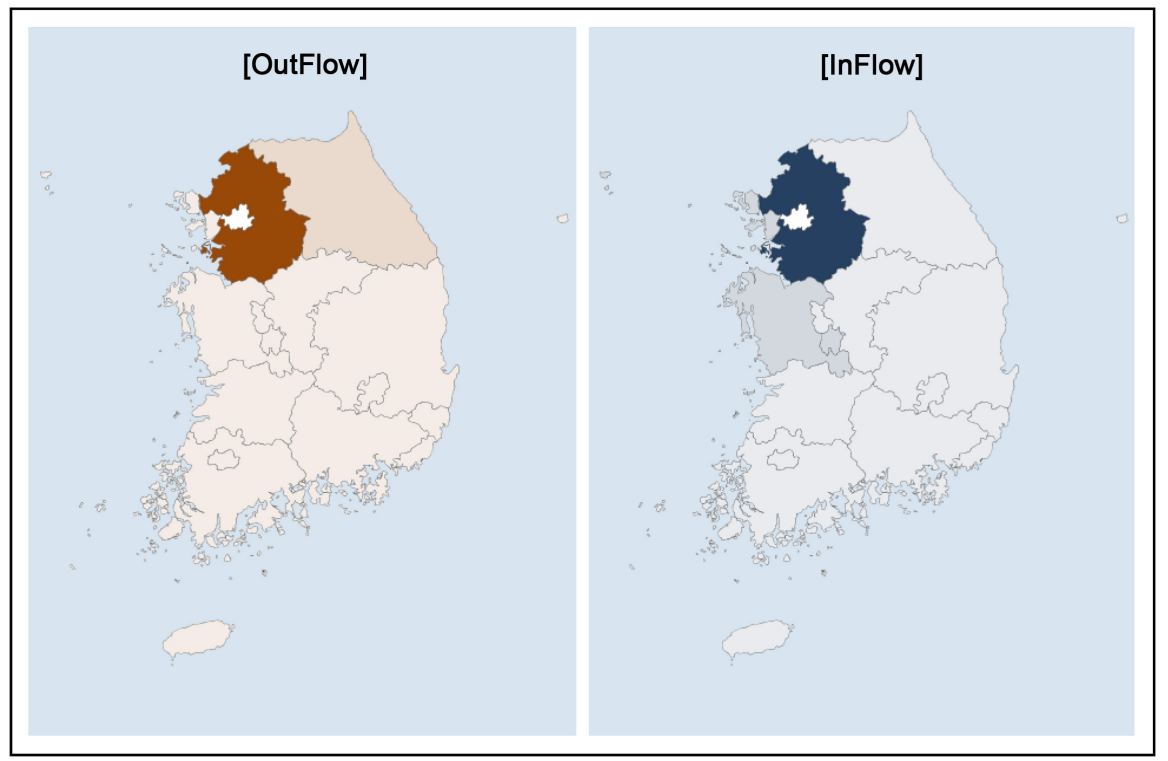

Figure 3. Net flows in Seoul high-growth company (region level).

shows the regional distribution of the entire moving companies, it is more evident that most of the companies which is moving from Seoul were moving within the Seoul metropolitan area.

For high-growth firms, it is important to find a location where they can easily acquire knowledge and labor, and the location requirements of the metropolitan area adjacent to the commodity market are very favorable (Table 9).

\section{Conclusions}

The cause of economic development in East Asia including Korea is various factors, but it is known that the role of government has contributed in part [8]. Since the 1990s, the goal of economic development policy in Korea is balanced development of the region, and company relocation is an important element of the policy. Therefore, looking at the spatial distribution of moving company is the first step in examining how the effect of the policy can be. 
Table 6. Company movement in Seoul (region level).

\begin{tabular}{|c|c|c|c|}
\hline \multirow{2}{*}{ Region } & \multicolumn{3}{|c|}{ Net flows (per company) } \\
\hline & Outflow & Inflow & Total \\
\hline Gangwon-do & 57 & 14 & -43 \\
\hline Gyeonggi-do & 1939 & 579 & -1360 \\
\hline Gyeongsangnam-do & 34 & 25 & -9 \\
\hline Gyeongsangbuk-do & 50 & 36 & -14 \\
\hline Gwangju & 25 & 21 & -4 \\
\hline Daegu & 17 & 21 & 4 \\
\hline Daejeon & 29 & 35 & 6 \\
\hline Busan & 59 & 43 & -16 \\
\hline Seoul & 5656 & 5656 & - \\
\hline Sejong & 10 & 2 & -8 \\
\hline Ulsan & 14 & 12 & -2 \\
\hline Incheon & 137 & 86 & -51 \\
\hline Jeollanam-do & 33 & 23 & -10 \\
\hline Jeollabuk-do & 32 & 13 & -19 \\
\hline Jeju-do & 23 & 5 & -18 \\
\hline Chungcheongnam-do & 76 & 30 & -46 \\
\hline Chungcheongbuk-do & 49 & 33 & -16 \\
\hline Total & 8240 & 6634 & -1606 \\
\hline
\end{tabular}

This study analyzes company data to establish a demand zone for estimating industrial complex demand, and based on this data, O-D tables for city and district are prepared. In the analysis, we examined how the regional characteristics appear in the O-D Table results. The purpose of this study is to set the demand impact area for each city and district based on the prepared O-D Table. As with estimating housing demand, estimating demand for industrial complexes by setting impact zones will contribute to supplementing existing quantitative methods and surveys.

In this study, spatial migration of firms occurred in the metropolitan area, and migration to other regions was partially transferred to neighboring areas such as Gangwon-do and Chungcheongnam-do. Especially, for companies with high growth potential, the movements in the metropolitan area were more prominent. It is more important to create a favorable environment for business activities rather than policy incentives, so creating an industrial infrastructure within the region will be most important.

This study concludes that the level of reviewing the limitations of existing 
Table 7. Company movement in Gangnam-gu (district level).

\begin{tabular}{|c|c|c|c|}
\hline \multirow{2}{*}{ District $(\mathrm{Gu})$} & \multicolumn{3}{|c|}{ Net flows (per company) } \\
\hline & Outflow & Inflow & Total \\
\hline Seocho & 361 & 319 & -42 \\
\hline Sungdong & 160 & 38 & -122 \\
\hline Songpa & 145 & 75 & -70 \\
\hline Jung & 105 & 76 & -29 \\
\hline Youngdeungpo & 61 & 45 & -16 \\
\hline Geumchun & 57 & 36 & -21 \\
\hline Mapo & 56 & 58 & 2 \\
\hline Yongsan & 45 & 36 & -9 \\
\hline Guro & 41 & 26 & -15 \\
\hline Jongro & 32 & 33 & 1 \\
\hline Gangdong & 27 & 18 & -9 \\
\hline Gangjin & 24 & 25 & 1 \\
\hline Ganak & 14 & 10 & -4 \\
\hline Gangseo & 12 & 12 & 0 \\
\hline Dongdaemun & 11 & 14 & 3 \\
\hline Dongjak & 9 & 7 & -2 \\
\hline Sungbuk & 9 & 8 & -1 \\
\hline Seodaemun & 7 & 12 & 5 \\
\hline Dobong & 6 & 2 & -4 \\
\hline Yangchun & 6 & 5 & -1 \\
\hline Jungrang & 6 & 3 & -3 \\
\hline Nowon & 5 & 5 & 0 \\
\hline Gangbuk & 3 & 3 & 0 \\
\hline Enpyung & - & 10 & 10 \\
\hline Others & 494 & 214 & -280 \\
\hline Total & 1696 & 1090 & \\
\hline
\end{tabular}

industrial complex demand estimation methods and presenting the O-D table on the demand zone setting for improvement of future demand estimation method.

The most difficult point in industrial research is the availability of useful statistical data. In academic research, this study is very useful in that it can acquire company transfer information by only annual data on company basic status. If we can study the changes in the distribution and characteristics of industries in 
Table 8. O-D Table about moving company-high-growth company (region level).

\begin{tabular}{|c|c|c|c|c|c|c|c|c|c|c|c|c|c|c|c|c|c|c|}
\hline \multirow{2}{*}{$\begin{array}{c}\text { Moving } \\
\text { out }\end{array}$} & \multicolumn{18}{|c|}{ Moving in } \\
\hline & $\mathrm{R} 1$ & $\mathrm{R} 2$ & $\mathrm{R} 3$ & $\mathrm{R} 4$ & $\mathrm{R} 5$ & $\mathrm{R} 6$ & R7 & $\mathrm{R} 8$ & R9 & $\mathrm{R} 10$ & $\mathrm{R} 11$ & $\mathrm{R} 12$ & $\mathrm{R} 13$ & $\mathrm{R} 14$ & $\mathrm{R} 15$ & $\mathrm{R} 16$ & $\mathrm{R} 17$ & Total \\
\hline $\mathrm{R} 1$ & 10 & 5 & - & - & - & - & - & - & 2 & - & - & - & - & 1 & - & - & - & 18 \\
\hline $\mathrm{R} 2$ & 9 & 232 & 2 & 7 & 4 & 4 & 1 & 9 & 52 & 4 & - & 20 & 3 & 4 & 2 & 20 & 12 & 385 \\
\hline R3 & - & - & 31 & - & 2 & - & 2 & 15 & 4 & 2 & 2 & - & 3 & 1 & 1 & 2 & 2 & 67 \\
\hline R4 & - & 1 & 2 & 23 & - & 11 & - & 2 & 4 & - & 4 & - & - & - & 1 & 3 & 1 & 52 \\
\hline R5 & - & 3 & - & - & 41 & - & - & - & - & 3 & - & - & 35 & 2 & - & 2 & - & 86 \\
\hline R6 & - & 1 & - & 11 & - & 31 & - & - & 2 & - & - & - & - & - & - & - & - & 45 \\
\hline R7 & - & 3 & 3 & - & - & 1 & 36 & - & 5 & 9 & - & - & - & - & - & 7 & 2 & 66 \\
\hline $\mathrm{R} 8$ & - & 4 & 16 & 2 & - & 1 & - & 87 & 2 & - & 2 & - & 1 & - & - & - & - & 115 \\
\hline R9 & 11 & 109 & - & 4 & - & 1 & 2 & 2 & 405 & 1 & 2 & 10 & 5 & 4 & 1 & 3 & 5 & 565 \\
\hline R10 & - & 2 & - & - & 2 & - & 1 & - & - & - & - & 2 & 2 & 1 & - & 6 & 2 & 18 \\
\hline R11 & - & - & 1 & 6 & - & - & - & 3 & - & - & 21 & - & - & - & - & - & - & 31 \\
\hline $\mathrm{R} 12$ & 2 & 27 & - & 1 & - & - & 1 & - & 8 & - & - & 33 & - & 1 & 1 & 5 & 1 & 80 \\
\hline R13 & - & 2 & - & - & 20 & 1 & - & 2 & 1 & - & - & - & 59 & 3 & - & 1 & - & 89 \\
\hline R14 & - & 4 & - & 1 & 1 & - & - & - & 2 & - & - & - & 4 & 19 & - & 1 & - & 32 \\
\hline R15 & - & 1 & - & - & - & - & - & - & - & - & - & - & - & - & 2 & - & - & 3 \\
\hline R16 & - & 7 & - & - & - & 2 & 2 & - & 5 & 2 & 1 & - & 3 & 2 & 1 & 31 & 1 & 57 \\
\hline R17 & - & 3 & 1 & 1 & - & - & 3 & - & 1 & 3 & - & - & - & 1 & - & 2 & 10 & 25 \\
\hline Total & 32 & 404 & 56 & 56 & 70 & 52 & 48 & 120 & 493 & 24 & 32 & 65 & 115 & 39 & 9 & 83 & 36 & 1734 \\
\hline
\end{tabular}

Notes: R1 (Gangwon-do), R2 (Gyeonggi-do), R3 (Gyeongsangnam-do), R4 (Gyeongsangbuk-do), R5 (Gwangju), R6 (Daegu), R7 (Daejeon), R8 (Busan), R9 (Seoul), R10 (Sejong), R11 (Ulsan), R12 (Incheon), R13 (Jeollanam-do), R14 (Jeollabuk-do), R15 (Jeju-do), R16 (Chungcheongnam-do), R17 (Chungcheongbuk-do).

the region through the basic data of the companies, it will be able to complement the existing survey methods for enterprise research and statistics generation. In the practical social area, this study can contribute to the demand estimation of industrial sites for regional development and the achievement of the policy goal of regional industrial development. From the viewpoint of balanced regional development, it will be possible to provide the transfer demand of the enterprises, and thus provide the basis for establishing policies such as the creation or remodeling of industrial complexes. If we complement the various characteristics of the enterprise, it can be used as a basic data for understanding and predicting the overall trend of the inter-regional or inter-country industry. In future research, we will find out how the movement of industry is different according to industry and scale, and contribute to the actual demand estimation for future 
Table 9. Company movement in Seoul-high-growth company (region level).

\begin{tabular}{|c|c|c|c|}
\hline \multirow{2}{*}{ Region } & \multicolumn{3}{|c|}{ Net flows (per company) } \\
\hline & Outflow & Inflow & Total \\
\hline Gangwon-do & 11 & 2 & -9 \\
\hline Gyeonggi-do & 109 & 52 & -57 \\
\hline Gyeongsangnam-do & - & 4 & 4 \\
\hline Gyeongsangbuk-do & 4 & 4 & - \\
\hline Gwangju & - & - & - \\
\hline Daegu & 1 & 2 & 1 \\
\hline Daejeon & 2 & 5 & 3 \\
\hline Busan & 2 & 2 & - \\
\hline Seoul & 405 & 405 & - \\
\hline Sejong & 1 & - & -1 \\
\hline Ulsan & 2 & - & -2 \\
\hline Incheon & 10 & 8 & -2 \\
\hline Jeollanam-do & 5 & 1 & -4 \\
\hline Jeollabuk-do & 4 & 2 & -2 \\
\hline Jeju-do & 1 & - & -1 \\
\hline Chungcheongnam-do & 3 & 5 & 2 \\
\hline Chungcheongbuk-do & 5 & 1 & -4 \\
\hline Total & 565 & 493 & -72 \\
\hline
\end{tabular}

industrial parks such as high-tech industrial complexes.

\section{References}

[1] Kim, H.B. and Choi, J.S. (2010) Forecasting Regional and Industrial Land Demand: The Case of Korea. Journal of the Korean Urban Management Association, 23, 215-236.

[2] Lee, H.J. and Kim, M.S. (2011) The Variation of Industrial Location Demand by Changing Policy of Seoul Metropolitan Area. Journal of the Economic Geographical Society of Korea, 14, 286-306. https://doi.org/10.23841/egsk.2011.14.3.286

[3] Cho, K.Y., Park, H.S. and Jung, I.H. (2008) A Study on the Forecast of Industrial Land Demand and the Location Decision of Industrial Complexes-In Case of Anseong City. Journal of Korean Society of Rural Planning, 14, 37-51.

[4] Park, J.K. and Bun, C.W. (2013) Forecasting the Size of the Industrial Land Employing the Panel Co-Integration Relationship. Korea Review of Applied Economics, 15, 73-101.

[5] Sun, C., et al. (2016) Urban Land Development for Industrial and Commercial Use: A Case Study of Beijing. Sustainability, 8, 1-18. https://doi.org/10.3390/su8121323

[6] Lin, S.-W. and Ben, T.-M. (2009) Impact of Government and Industrial Agglomera- 
tion on Industrial Land Prices: A Taiwanese Case Study. Habitat International, 33, 412-418. https://doi.org/10.1016/j.habitatint.2009.01.001

[7] Weng, Q. (2002) Land Use Change Analysis in the Zhujiang Delta of China Using Satellite Remote Sensing, GIS and stochastic Modelling. Journal of Environmental Management, 64, 273-284. https://doi.org/10.1006/jema.2001.0509

[8] Ko, Y.S. (2008) Korea's Economic Growth and Government's Role: Past, Present and Future. Korea Development Institute, Sejong, 143-145. 